\title{
Smooth Torque Speed Characteristic of Switched Reluctance Motors
}

\author{
Hui Zeng ${ }^{*}$, Zhe Chen ${ }^{\dagger}$, and Hao Chen ${ }^{*}$ \\ *School of Information and Electrical Engineering, China University of Mining and Technology, Xuzhou, China \\ ${ }^{\dagger}$ Department of Energy Technology, Aalborg University, Aalborg, Denmark
}

\begin{abstract}
The torque ripple of switched reluctance motors (SRMs) is the main disadvantage that limits the industrial application of these motors. Although several methods for smooth-toque operation (STO) have been proposed, STO works well only within a certain torque and speed range because of the constraints of the supply voltage and peak current. Based on previous work that sought to expand the STO range, a scheme is developed in this study to determine the maximum smooth torque range at each speed. The relationship between the maximum smooth torque and speed is defined as the smooth torque speed characteristics (STSC), a concept similar to torque speed characteristics (TSC). STSC can be utilized to evaluate torque utilization by comparing it with TSC. Thus, the concept benefits the special design of SRMs, especially for the generation of smooth torque. Furthermore, the torque sharing function (TSF) derived from the proposed method can be applied to STO, which produces a higher smooth torque over a wider speed range in contrast to four typical TSFs. TSimulation and experimental results verify the proposed method.
\end{abstract}

Keywords: Operation range, Switched reluctance motor (SRM), Torque ripple reduction, Torque sharing function (TSF)

\section{INTRODUCTION}

Switched reluctance motors (SRMs) have a few advantages, such as low cost, robust construction, and excellent speed regulation performance. However, SRMs suffer from high torque ripple because of their doubly salient configuration and switched excitation pattern. This high torque ripple causes a noisy acoustic and limits the application of SRMs in the servo-type field. In the past few years, several technologies have been developed to simultaneously reduce the torque ripple of SRMs and minimize copper losses. These methods have performed as expected, particularly at low speed, through the use of closed-loop current controllers. Nevertheless, the level of torque ripple rises as speed increases because the finite converter supply voltage limits the ability of the current controller to track the reference value. Thus, the operational speed range of smooth-torque operation (STO) is restricted considerably by the supply voltage. Another problem for STO is that the operational smooth-torque range is restricted by the peak current, which is determined by the converter VA rating

Manuscript received Jul. 24, 2013; accepted Dec. 19, 2013

Recommended for publication by Associate Editor Dong-Hee Lee.

†Corresponding Author: hchen@cumt.edu.cn

Tel: +86-13013993107, Fax: +81-0516-83884587, China Univ. of Mining \& Tech.

*School of Information and Electrical Engineering, China University of Mining and Technology, China and the thermal tolerance of the phase windings.

Several previous studies on torque ripple minimization have considered the above constraints and developed approaches to expand the operation range, including speed and smooth-torque ranges. A balanced commutator method was presented in [1]. The peaks and rates of the change in reference currents were reduced; thus, a wider operation range was achieved. A critical angle at which two adjacent phases can produce the same torque with the same flux linkage was set as the commutation point in [2] and [3]; consequently, a large operational range of STO was realized. However, the effect of the winding resistor on the supply voltage was not considered. The harmonic current injection technique was described in [4]. A wide operational speed range was achieved with this method in [5] by combining switching angle control with a genetic algorithm (GA). However, the peak current was disregarded.

In [6]-[10], reference torque, current, and flux linkage were expressed by mathematic formulas, the parameters of which were optimized to expand the operational range. Four torque-sharing functions (TSFs) are typically applied in STO: linear, sinusoidal, cubic, and exponential. In [6], the parameters of the four TSFs were optimized by GA. The reference current was expressed by a small set of harmonic coefficients optimized by sequential quadratic programming in [7]. Another reference current expression with only a few variables (one to three variables) was developed to simplify the optimization 
procedure in [8]. A TSF with only one parameter was proposed in [9]; thus, the optimal result was easily acquired. A flux linkage profile directly related to phase voltage was created in [10]. The speed range was greatly extended, but the winding resistors and the peak current limit were not considered. All these aforementioned methods have a common disadvantage, that is, determining the maximum operational range of STO with a predefined mathematic formula is difficult because expressing the SRM model with a universal mathematic formula is also difficult.

H. C. Lovatt and J. M. Stephenson [11], [12] expressed the constrained optimization problem with standard formulas and resolved it by a commercial numerical routine (NAG library). Similar procedures were performed in [13], [14], but the algorithms were not elaborated. Numerical optimization method is more time consuming than analysis method. However, it is conducted offline and computers operate much faster nowadays. Thus, the computation time is acceptable.

At a low speed range, the maximum smooth torque remains constant because only the peak current limits it. However, at a high speed range, the expected smooth torque is reduced to ensure that the reference current (torque or flux linkage) can be traced completely. Thus, maximum smooth torque is a function of speed, a relation referred to in this paper as smooth-toque speed characteristics (STSC). STSC is a concept similar to torque speed characteristics (TSC). STSC and TSC represent the capacity to generate maximum smooth torque and maximum average torque, respectively.

This study explores the STSC of SRMs as well as the constraints of supply voltage and peak current. The key issue is to determine the TSF that requires the lowest voltage among all available TSFs that can be used as output for smooth torque, including the aforementioned TSFs. A numerical iterative method is proposed to acquire such TSF. STSC and TSC are compared to evaluate the utilization ratio of smooth torque with respect to the average torque. Thus, the study contributes in the special design of SRMs, particularly in the generation of smooth torque. The optimal TSF obtained from the proposed method is applicable within a very broad operation range unlike other TSFs. Furthermore, it is verified through the co-simulation of the multiple domain simulation software Simplorer and the finite element machine design software Ansoft and Simulink. The proposed method is also verified through an experiment.

The proposed scheme is based on the following assumptions.

1) Two phases conduct simultaneously at overlap intervals. The mutual magnetic coupling between the individual phases is neglected; thus, the total torque is the superposition of the phase torques.

2) The SRM is operated from the (AHB) converter. Hence, a voltage range $[-V, V]$ can be supplied, where $V$ denotes the supply voltage.

3) The peak current constraint is constant.

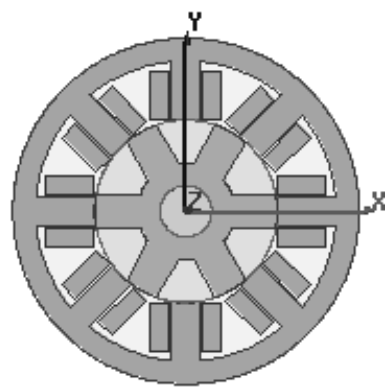

Fig. 1. Structure of the four-phase 8/6 SRM.
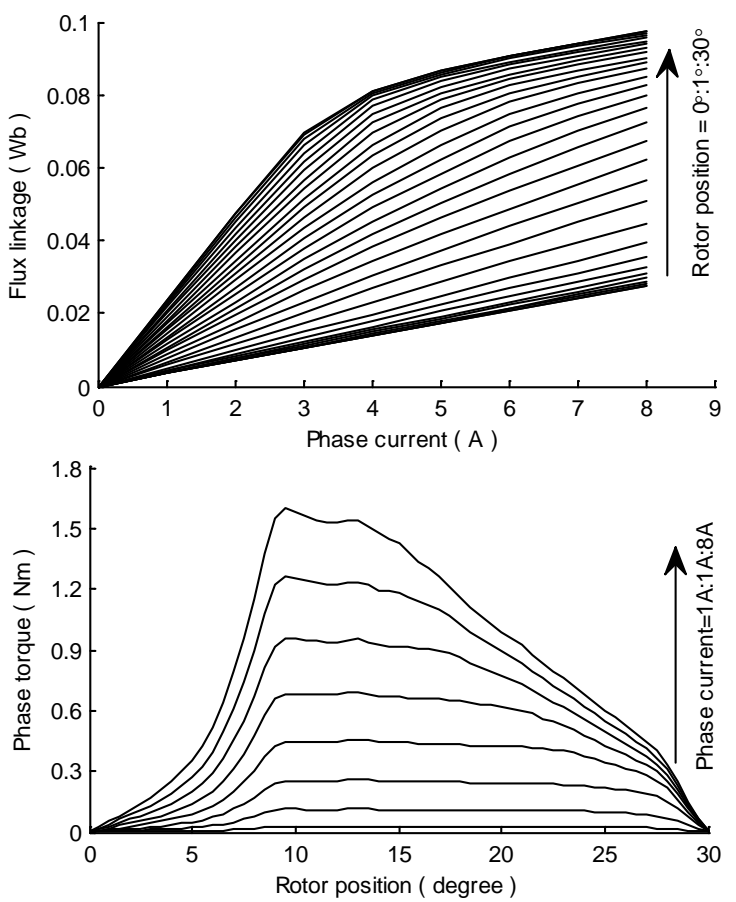

Fig. 2. Flux linkage and torque characteristics.

4) The speed is constant during a conductive period.

To describe the proposed method conveniently, $\left(\omega, T_{\mathrm{e}}\right)$ is defined as an operating point on the speed-torque plane; it denotes smooth torque $T_{\text {e }}$ produced at speed $\omega$.

\section{DETERMINATION OF SMOOTH-TORQUE CHARACTERISTIC}

\section{A. Introduction of the Prototype and TSFs}

An experimental four-phase 8/6 structure SRM (Fig. 1) is used to elaborate the proposed scheme. The $2 \mathrm{D}$ finite element method is used to compute the flux linkage characteristic $\psi(i$, $\theta$ ) and torque characteristic $T(i, \theta)$ (Fig. 2) by exciting a series of discrete currents in the single phase at discrete rotor positions. The functions $i(T, \theta)$ and $i(\psi, \theta)$ are derived from $T(i, \theta)$ and $\psi(i, \theta)$ with the numerical algorithm. The calculation of the proposed scheme is based on these four functions.

The individual phase inductance of the prototype changes cyclically at a $60^{\circ}$ position period (Fig. 3). To avoid negative 


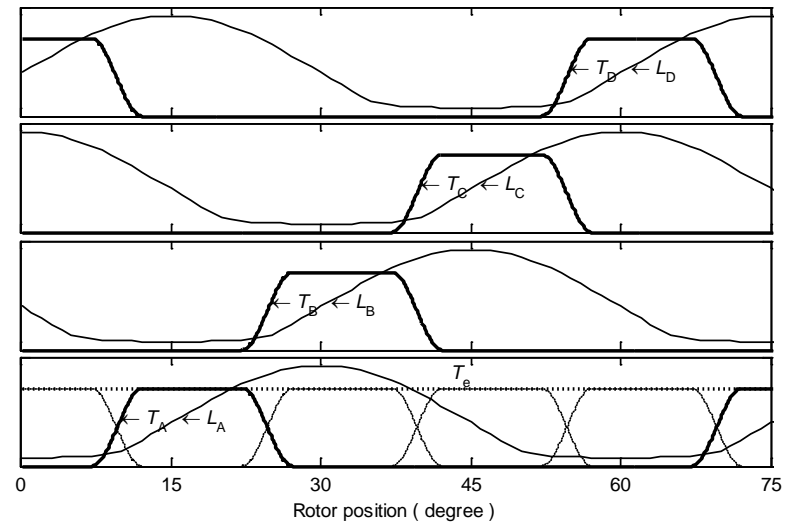

Fig. 3. Phase inductances $L_{\mathrm{k}}$ and distributed torques $T_{\mathrm{k}}(k \in\{\mathrm{A}$, $\mathrm{B}, \mathrm{C}, \mathrm{D}\})$.

torque generation, the conductive interval of each phase is set as $\left[0^{\circ}, 30^{\circ}\right]$, which is divided into two parts. For instance, in phase $\mathrm{A},\left[0^{\circ}, 15^{\circ}\right]$ is the overlap in which phases $\mathrm{D}$ and $\mathrm{A}$ simultaneously produce torque; $\left[15^{\circ}, 30^{\circ}\right]$ is the overlap in which phases $\mathrm{A}$ and $\mathrm{B}$ simultaneously produce torque. Therefore, two adjacent phases contribute to the total torque. To produce the total smooth torque, a TSF is developed as follows:

$$
T_{\mathrm{k}}(\theta)=\left\{\begin{array}{lr}
f(\theta), & 0^{\circ} \leq \theta \leq 15^{\circ} \\
T_{\mathrm{e}}-f\left(\theta-15^{\circ}\right), & 15^{\circ} \leq \theta \leq 30^{\circ}
\end{array}\right.
$$

where $T_{\mathrm{e}}$ is the expected total smooth torque. According to the category of $f(\theta)$, popular TSFs may be classified as linear [15], cubic [16], sinusoidal [17], and exponential [18] .

\section{B. TSF with the Lowest Required Voltage}

As mentioned in previous studies [7, 11-14], the following are the necessary and sufficient conditions for STO.

$$
\begin{gathered}
u_{\mathrm{r}} \leq V \\
u_{\mathrm{r}}=\max (|u(\theta)|) \\
u(\theta)=i\left(T_{\mathrm{k}}(\theta), \theta\right) \cdot r+\omega \cdot d \psi\left(T_{\mathrm{k}}(\theta), \theta\right) / d \theta \\
i_{\mathrm{ph}} \leq i_{\text {peak }}
\end{gathered}
$$

where $u_{\mathrm{r}}$ is the required voltage, $i_{\mathrm{ph}}$ is the phase current, and $i_{\text {peak }}$ is the peak current.

The operation range of STO can be effectively expanded by reducing $u_{\mathrm{r}}$. For a given SRM, $u_{\mathrm{r}}$ depends only on the TSF at a fixed operating point $\left(\omega, T_{\mathrm{e}}\right)$. Fig. 4 shows the effect of different TSFs on $u_{\mathrm{r}}$. Among the four TSFs, the $u_{\mathrm{r}}$ of the exponential TSF is the lowest. Thus, if the supply voltage is $150 \mathrm{~V}$, the STO using the exponential TSF can produce a higher smooth torque than the others.

Provided that such a TSF ${ }_{\text {opt }}$ exists, whose $u_{\mathrm{r}}$ is the lowest among all the available TSFs, including the aforementioned four TSFs, function $u_{r_{-} \min }\left(\omega, T_{\mathrm{e}}\right)$, which represents the minimum $u_{\mathrm{r}}$ at an operating point, can be established. The operating points that meet the condition $u_{r_{-} \min }\left(\omega, T_{\mathrm{e}}\right) \leq V$

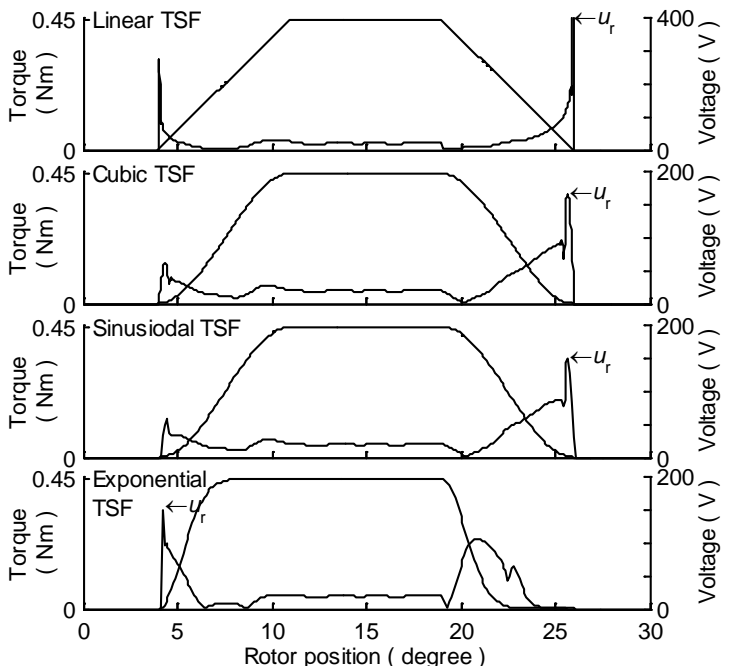

Fig. 4. Required phase voltage of the four TSFs $(\omega=800 \mathrm{rpm}$, $\left.T_{\mathrm{e}}=0.45 \mathrm{Nm}\right)$

form a set on the speed-torque plane. The set is exactly the maximum operation range of STO. The boundary of this set constitutes the STSC curve. Therefore, the key to determine STSC is to identify TSF $_{\text {opt }}$ (discussed in Section $D$ ).

\section{Maximum Smooth Torque}

Given the peak current limit, the maximum individual phase torque is

$$
T_{\text {max }}(\theta)=T\left(i_{\text {peak }}, \theta\right) .
$$

Thus, TSF should be constrained by

$$
\begin{gathered}
0^{\circ} \leq \theta \leq 15^{\circ} \\
0 \leq T_{\mathrm{e}}-f\left(\theta-15^{\circ}\right) \leq T_{\max }(\theta), 15^{\circ} \leq \theta \leq 30^{\circ} .
\end{gathered}
$$

Another constraint is derived from Eq. (7) as follows:

$$
\begin{aligned}
& 0 \leq f(\theta) \leq T_{\max }(\theta), \quad 0^{\circ} \leq \theta \leq 15^{\circ} \quad \Leftrightarrow \\
& 0 \leq f\left(\theta-15^{\circ}\right) \leq T_{\max }(\theta), \quad 15^{\circ} \leq \theta \leq 30^{\circ} \Leftrightarrow \\
& T_{\mathrm{e}}-T_{\max }\left(\theta-15^{\circ}\right) \leq T_{\mathrm{e}}-f\left(\theta-15^{\circ}\right) \leq T_{\mathrm{e}}, 15^{\circ} \leq \theta \leq 30^{\circ} .
\end{aligned}
$$

Another constraint is also derived from from Eq. (8) as follows:

$$
\begin{gathered}
0 \leq T_{\mathrm{e}}-f\left(\theta-15^{\circ}\right) \leq T_{\max }(\theta), \quad 15^{\circ} \leq \theta \leq 30^{\circ} \Leftrightarrow \\
0 \leq T_{\mathrm{e}}-f(\theta) \leq T_{\max }\left(\theta+15^{\circ}\right), \quad 0^{\circ} \leq \theta \leq 15^{\circ} \Leftrightarrow \\
T_{\mathrm{e}}-T_{\max }\left(\theta+15^{\circ}\right) \leq f(\theta) \leq T_{\mathrm{e}}, \quad 0^{\circ} \leq \theta \leq 15^{\circ} .
\end{gathered}
$$

Thus, TSF is constrained by Eqs. (7) and (10) in the interval $\left[0^{\circ}, 15^{\circ}\right]$ and by Eqs. (8) and (9) in the interval $\left[15^{\circ}, 30^{\circ}\right]$. The range determined by these constraints is denoted by the gray area in Fig. 5. If $T_{\mathrm{e}}$ is less than or equal to $1.3 \mathrm{Nm}$, the TSFs are located in the gray domain (Fig. 5(a)). If $T_{\mathrm{e}}$ is more than $1.3 \mathrm{Nm}$, the gray domain in the interval $\left[0^{\circ}, 15^{\circ}\right]$ is divided into two disconnected areas, which means no TSF is available (Fig. 5(b)). Therefore, $T_{\mathrm{e}}=1.3 \mathrm{Nm}$ is the maximum smooth torque determined by the peak current; it can be 


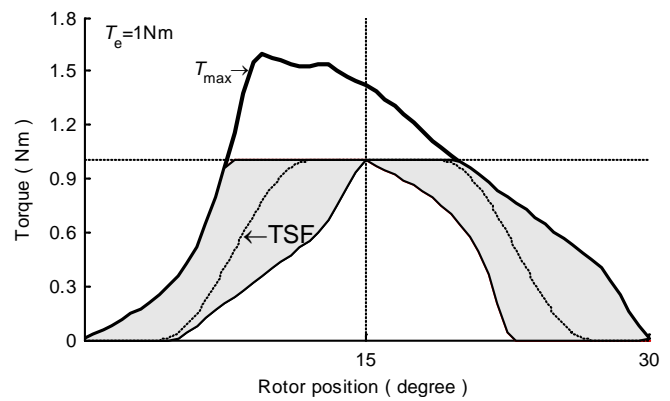

(a)

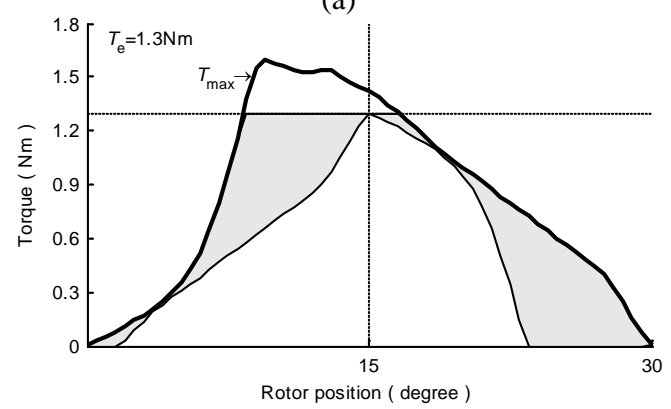

(b)

Fig. 5. Determination of the maximum smooth torque.

generated only at low speed because of the supply voltage limit.

\section{Determination of TSF $F_{\text {opt }}$}

The optimization problem can be expressed as Optimization objective: $\min \left(u_{\mathrm{r}}\right)$

Constraint condition: $\quad 0 \leq i_{\text {ph }} \leq i_{\text {peak }}$

$$
0 \leq \theta \leq 30^{\circ}
$$

where $u_{\mathrm{r}}$ is expressed by Eqs. (3) and (4).

Applying the numerical optimization method, Eqs. (3) and (4) are discretized to Eqs. (14) and (15) as

$$
\begin{gathered}
u_{\mathrm{r}}=\max (|u(\tau \cdot \Delta \theta)|)=\left|u\left(\tau_{\max } \cdot \Delta \theta\right)\right| \\
u(\tau \cdot \Delta \theta)=i\left(T_{\mathrm{k}}(\tau \cdot \Delta \theta), \tau \cdot \Delta \theta\right) \cdot r \\
+\omega \cdot \frac{\psi\left(T_{\mathrm{k}}(\tau \cdot \Delta \theta), \tau \cdot \Delta \theta\right)-\psi\left(T_{\mathrm{k}}((\tau-1) \cdot \Delta \theta),(\tau-1) \cdot \Delta \theta\right)}{\Delta \theta} \\
\Delta \theta=0.1^{\circ}, \tau \in\{1,2,3, \cdots, 300\}
\end{gathered}
$$

where $\tau_{\max } \cdot \Delta \theta$ denotes the rotor position wherein the absolute value of the voltage reaches its maximum.

An iterative algorithm is proposed to solve this problem. The $u_{\mathrm{r}}$ and $\tau_{\max }$ of the present TSF are calculated at every iteration. The shape of the TSF is then optimized by regulating the reference torque value at $\tau_{\max } \cdot \Delta \theta$ or $\left(\tau_{\max }-1\right) \cdot \Delta$ $\theta$ to decrease $u_{\mathrm{r}}$. Finally, TSF $\mathrm{opt}_{\text {ot }}$ with $u_{\mathrm{r} \_ \text {min }}$ is acquired. The process is detailed in Fig. 6.

The steps marked by numbers in Fig. 6 are explained as follows.

1. Any TSF may be used as the initial TSF. However, a good selection helps reduce the computation cost. In this study, the sinusoidal TSF is adopted. The initial TSF is discretized and is expressed by Parameters $\tau_{\text {on }}$

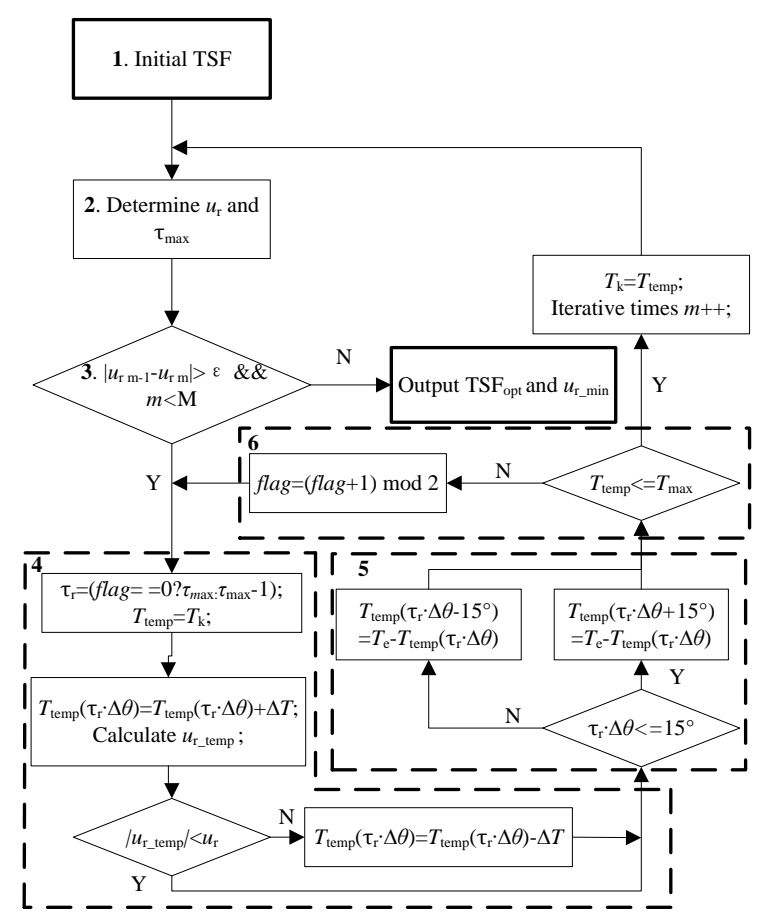

Fig. 6. Procedure of the iterative algorithm.

$$
T_{\mathrm{k}}(\tau \cdot \Delta \theta)=\left\{\begin{array}{lr}
0, & \leq \tau \leq \tau_{\text {on }} \\
\frac{T_{\mathrm{e}}}{2}-\frac{T_{\mathrm{e}}}{2} \cos \left[\frac{\pi}{\tau_{\mathrm{ov}}}\left(\tau-\tau_{\text {on }}\right)\right], & \tau_{\text {on }} \leq \tau \leq \tau_{\text {on }}+\tau_{\text {ov }} \\
T_{\mathrm{e}}, & \tau_{\text {on }}+\tau_{\text {ov }} \leq \tau \leq \frac{15^{\circ}}{\Delta \theta} \\
T_{\mathrm{e}}-T_{\mathrm{k}}\left(\tau \cdot \Delta \theta-15^{\circ}\right), & \frac{15^{\circ}}{\Delta \theta} \leq \tau \leq \frac{30^{\circ}}{\Delta \theta} \\
\tau \in\{0,1,2, \cdots, 300\} .
\end{array}\right.
$$

and $\tau_{\mathrm{ov}}$ can be optimized to yield the lowest $u_{\mathrm{r}}$ among all the sinusoidal TSFs as performed with GA in [6]. In the present study, traversal method is implemented for the optimization.

2. $u_{\mathrm{r}}$ and $\tau_{\max } \cdot \Delta \theta$ are calculated by Eqs. (14) and (15).

3. This judgment determines whether the iteration routine should end or not. If the dropping amplitude of $u_{\mathrm{r}}$ is less than the tiny constant $\varepsilon$ or if the iterative time is more than the maximum iterative time $\mathrm{M}$, the routine ends and the final results, $\mathrm{TSF}_{\mathrm{opt}}$ and $u_{r_{-} \min }$, are produced. Otherwise, step 4 is executed.

4. In this step, the shape of the current TSF changes to reduce $u_{\mathrm{r}}$. According to Eq. (15), the reference torque value can be regulated to reduce $u_{\mathrm{r}}$ at either $\tau_{\max } \cdot \Delta \theta$ or $\left(\tau_{\max }-1\right) \cdot \Delta \theta$. Which one to select depends on the boolean variable flag. If flag is $0, \tau_{\max } \cdot \Delta \theta$ is selected. Then, at the selected position $\tau_{\mathrm{r}} \cdot \Delta \theta$, the reference torque value is regulated by adding $\Delta T$.

$$
\Delta T=\frac{T_{\mathrm{k}}\left(\tau_{\mathrm{r}} \cdot \Delta \theta\right)}{p}
$$



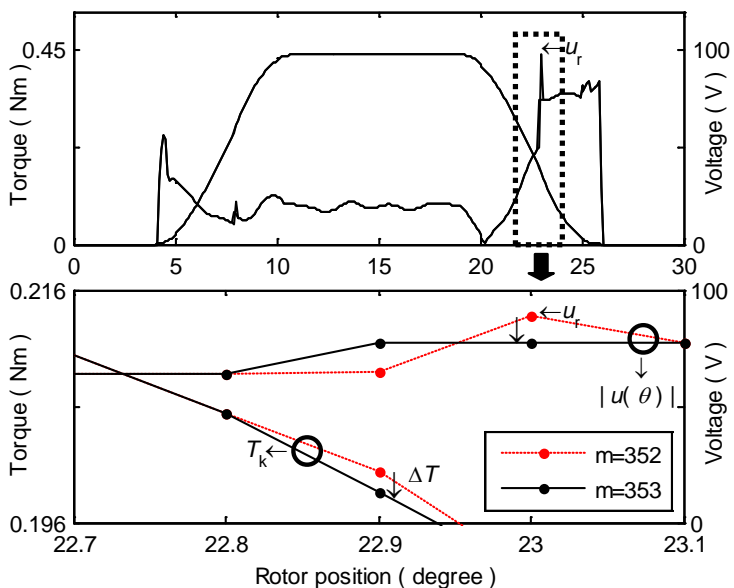

Fig. 7. Waveforms of $T_{\mathrm{k}}$ and $|u(\theta)|$ in the iterative procedure $\left(\omega=800 \mathrm{rpm}, T_{\mathrm{e}}=0.45 \mathrm{Nm}\right)$.

where $p$ is a constant coefficient that affects the convergence rate and the precision of the results.

The results of the regulation are checked by comparing $u_{\mathrm{r}}$ with $u_{\mathrm{r} \text { temp }}$ that denotes the required voltage of the reshaped TSF calculated by

$u_{\mathrm{r}_{-} \text {temp }}=i\left(T_{\text {temp }}\left(\tau_{\mathrm{r}} \cdot \Delta \theta\right), \tau_{\mathrm{r}} \cdot \Delta \theta\right) \cdot r+\omega$.

$\frac{\psi\left(T_{\text {temp }}\left(\tau_{\mathrm{r}} \cdot \Delta \theta\right), \tau_{\mathrm{r}} \cdot \Delta \theta\right)-\psi\left(T_{\text {temp }}\left(\left(\tau_{\mathrm{r}}-1\right) \cdot \Delta \theta\right),\left(\tau_{\mathrm{r}}-1\right) \cdot \Delta \theta\right)}{\Delta \theta}$

where $T_{\text {temp }}$ is the reshaped TSF in step 3. If $u_{\mathrm{r}_{-} \text {temp }}$ is less than $u_{\mathrm{r}}, u_{\mathrm{r}}$ can be reduced. Thus, the regulation is valid. Otherwise, $\Delta T$ is replaced by $-\Delta T$.

This step is demonstrated in Fig. 7. The current TSF and $|u(\theta)|$ are denoted by the solid line. The maximum value of $|u(\theta)|$, namely, $u_{\mathrm{r}}$, is determined at $23^{\circ}$. Given that flag is 1 , reference torque $T_{\mathrm{k}}\left(22.9^{\circ}\right)$ is regulated by subtracting $\Delta T$; this procedure causes a reduction in $u_{\mathrm{r}}$. The reshaped TSF and $|u(\theta)|$ are indicated by the dotted line.

5. According to Eq. (1), if a reference torque value changes within $\left[0^{\circ}, 15^{\circ}\right]$ or $\left[15^{\circ}, 30^{\circ}\right]$, the corresponding value in $\left[15^{\circ}, 30^{\circ}\right]$ or $\left[0^{\circ}, 15^{\circ}\right]$ should also change.

6. The constraint of the peak current is converted to the constraint of maximum torque $T_{\max }$ by Eq. (6). If the reshaped TSF denoted by $T_{\text {temp }}$ does not exceed $T_{\max }, T_{\text {temp }}$ is available and is assigned to $T_{\mathrm{k}}$ as the input of the next iteration. Otherwise, $T_{\text {temp }}$ should be abandoned and steps 2 to 5 are repeated after flag flips.

In steps 2 to $6, u_{\mathrm{r}}$ drops at every iteration until it approaches a constant value. The voltage $\Delta u=125.4 \mathrm{~V}$ is reduced, and $\mathrm{TSF}_{\text {opt }}$ is acquired as depicted in Fig. 8.

Different TSFs are set as the initial TSF. The same optimal result is obtained.

\section{E. STSC}

A corresponding $u_{r_{\_} \min }$ exists at each operating point. A 2D table of $u_{\mathrm{r} \_ \text {min }}$ versus a series of discrete operating points over the speed-torque plane is calculated and is described by

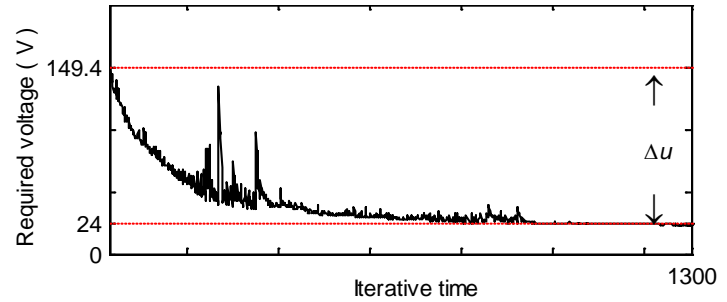

(a) Reduction in $u_{\mathrm{r}}$ during the iterative process.

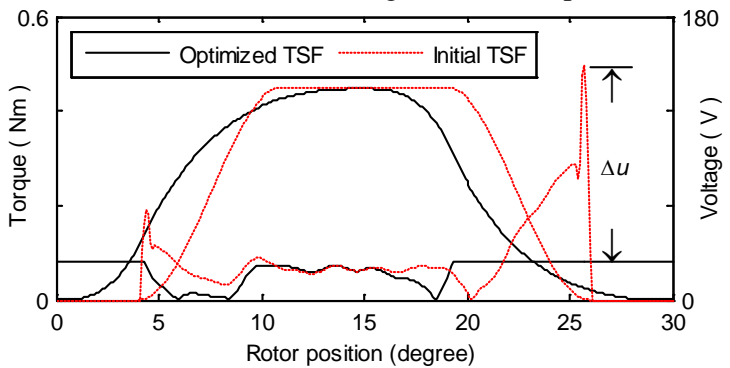

(b) Waveforms of the initial TSF and TSF $_{\text {opt }}$ and their phase voltage curves.

Fig. 8. Determination of TSF $\mathrm{opt}_{\mathrm{t}}$.

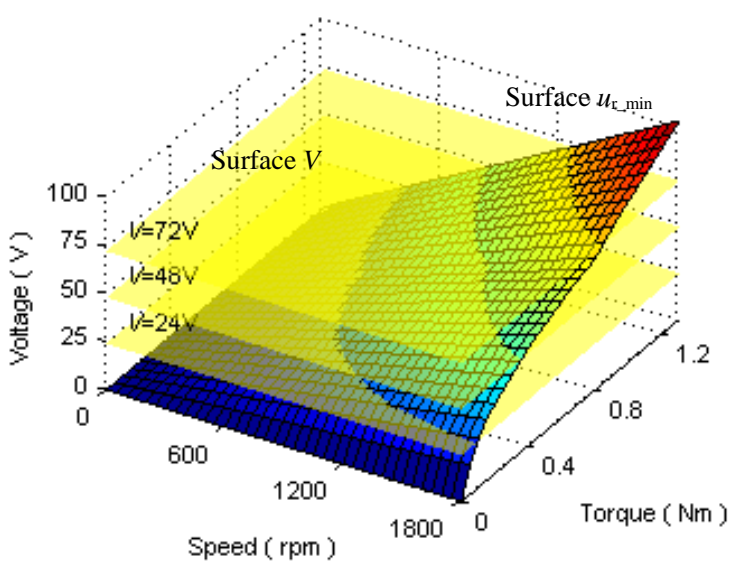

Fig. 9. $u_{r_{-} \min }$ versus smooth torque and speed.

surface $u_{r_{\_} \min }$ (Fig. 9). The other surface is also determined to denote supply voltage $V$. Clearly, surface $V$ cuts surface $u_{r_{-} \min }$ into two parts. The projection of the underside of the speed-torque plane is exactly the maximum operation range of STO according to Eq. (2). The projection of the intersection of the two surfaces is the STSC (Fig. 10).

The TSC of the prototype is described in Fig. 10. The STSC curve is similar to the TSC curve, and STSC is located under TSC. Comparison of the two curves indicates the torque utilization rate of STO, which benefits the special design of SRMs in generating smooth torque.

The operation ranges of the four TSFs are provided; these ranges differ from the maximum operation range. $\mathrm{TSF}_{\mathrm{opt}}$ can be utilized for STO. It produces a higher smooth torque over a larger speed range compared with the other four TSFs as verified in the next section.

High supply voltages significantly expand the range of STSC (Fig. 11). However, the improvement of the VA rating 


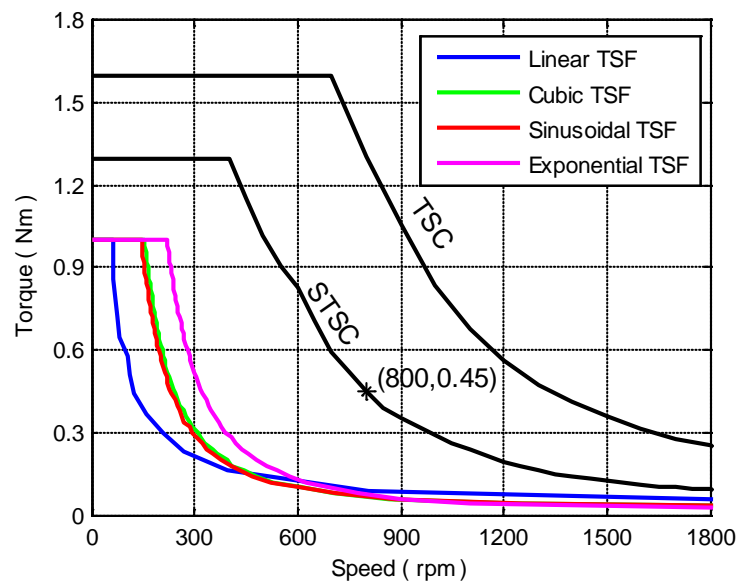

Fig. 10. Comparison of STSC, TSC, and the operation ranges of the four TSFs $\left(V=24 \mathrm{~V}, i_{\text {peak }}=8 \mathrm{~A}\right)$.

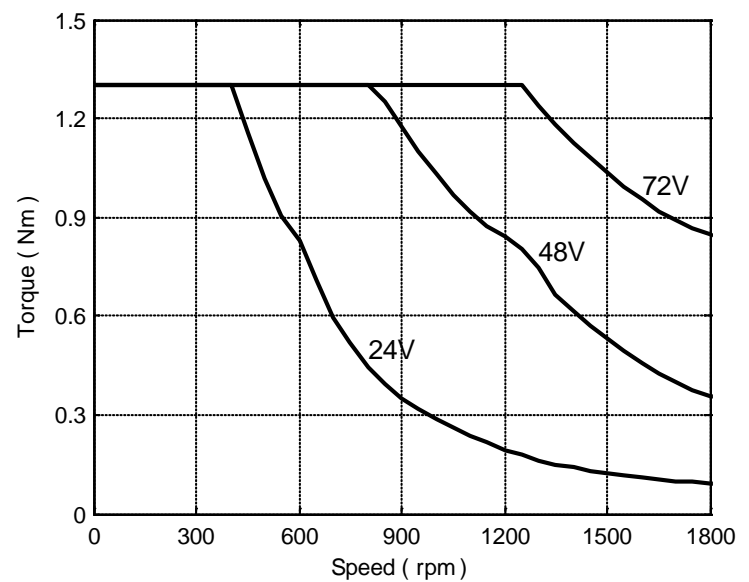

Fig. 11. STSC versus different supply voltages.

entails additional economic cost. Thus, a trade-off between operation range and cost should be made.

\section{F. Commonality of TSF opt}

The shapes of the $\mathrm{TSF}_{\text {opt }} \mathrm{s}$ with respect to the different operating points vary. However, they still have a commonality. The voltage profile at the intervals $\left[\theta_{\text {on }}, \theta_{\text {off }}-15^{\circ}\right]$ is flat and equal to $u_{\mathrm{r}}$, the maximum voltage. Thus, the phase current can increase to the required level in the shortest possible time. The voltage profile at $\left[\theta_{\text {off }}, 30^{\circ}\right]$ is also flat and equal to $-u_{\mathrm{r}}$; this condition ensures that the freewheeling current drops to zero as quickly as possible. This feature can also be seen in [3] and [11]. In [3], a method was proposed to expand the operation range of STO without considering the winding resistor. In [11], a commercial numerical routine (NAG library) was utilized to optimize TSF.

The $\mathrm{TSF}_{\text {opt }} \mathrm{S}$ at different speeds on the STSC curve are shown in Fig. 12. The required voltage is $24 \mathrm{~V}$, which is the nominal supply voltage. As the speed increases, the turn-on and turn-off angles move forward and expand angle scopes $\left[\theta_{\text {on }}, \theta_{\text {off }}-15^{\circ}\right]$ and $\left[\theta_{\text {off }}, 30^{\circ}\right]$. At a high speed, $\left[\theta_{\text {on }}, \theta_{\text {off }}-15^{\circ}\right]$ and $\left[\theta_{\text {off }}, 30^{\circ}\right]$ should be extended to provide sufficient time

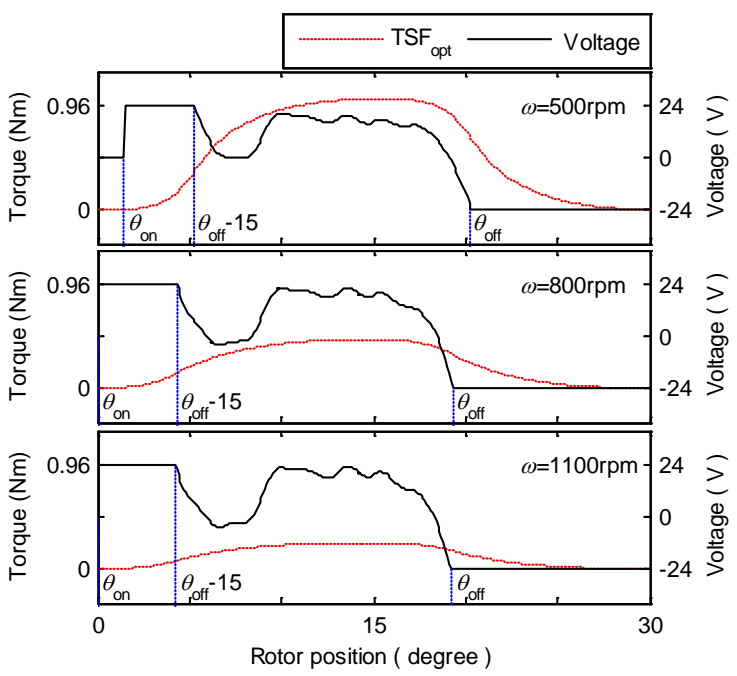

Fig. 12. Optimized TSFs at different speeds on the STSC curve.

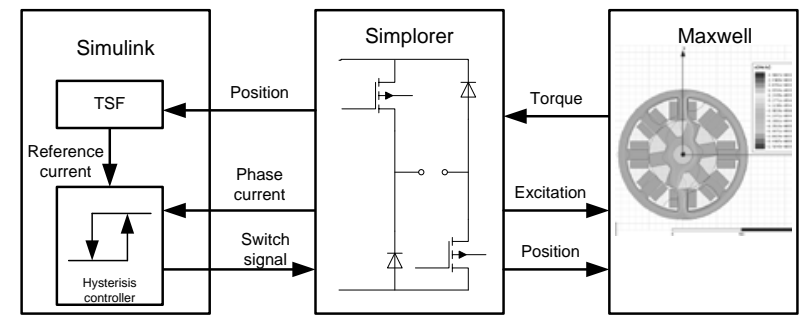

Fig. 13. Co-simulation model.

for magnetic excitation and demagnetization.

\section{VERIFICATION}

The best means to verify STSC is to test all available TSFs at every operating point located on the STSC curve. If the torque ripple can be eliminated only by $\mathrm{TSF}_{\text {opt }}$ rather than the other TSFs, the proposed STSC is valid. However, this condition is practically impossible to obtain because infinite TSFs and operating points exist. In this section, the four typical TSFs and $\mathrm{TSF}_{\text {opt }}$ at one point (800 rpm, $0.45 \mathrm{Nm}$ ) are tested and their STO performances are compared.

\section{A. Simulation}

To ensure that the simulation is precise, the $2 \mathrm{D}$ finite element model of SRM is applied directly through co-simulation technology (Fig. 13). At every simulation step, the software Maxwell calculates the transient magnetic field after excitation and the rotor position are determined. The total torque is then produced. In the multiple-domain simulation software Simplorer, the mechanical equation is solved to produce the speed and rotor position with the torque input. To simplify the problem, rotation speed is manually set as a constant. The AHB converter is simulated to supply the excitation with the input of the switch signals. In Simulink, the current hysteresis control is executed to provide the switch signals with the feedback of the position and phase 


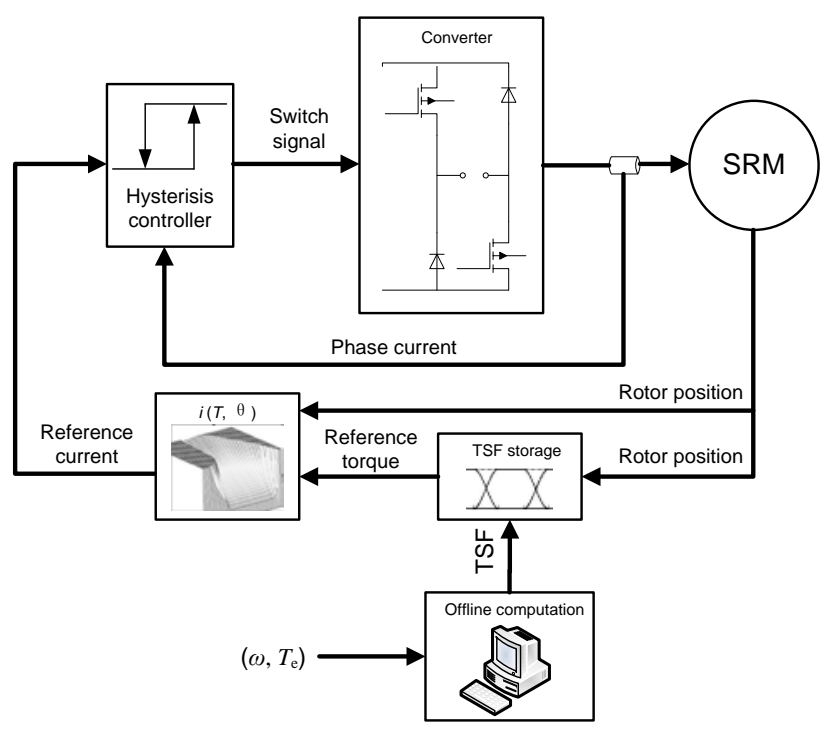

Fig. 14. STO based on the current hysteresis controller.

current.

\section{B. Control Approach}

The STO at the operating point (800 rpm, $0.45 \mathrm{Nm}$ ) on the STSC curve is executed. Fig. 14 shows a block diagram of the system.

Before the system operates, the four TSFs and $\mathrm{TSF}_{\text {opt }}$ are computed offline and are saved as 2D tables in the TSF storage. The parameters of the four typical TSFs are profiled to ensure that the reference phase current is less than the peak current $(8 \mathrm{~A})$. When the system is running, the phase reference torque is acquired through the lookup table method. The reference torque is converted to the reference current by the function $i(T, \theta)$ online. The conventional hysteresis controller, which is simple and effective, is adopted to control the phase current and trace the reference current.

\section{Simulation Results}

Figs. 15(a) to 15(d) show the torque performances of the STO using the four TSFs. At the position $\left.\theta\right|_{u(\theta)>V}$, the increment rate of the practical current is less than that of the reference current even though the phase is excited by entire supply voltage $V$. Thus, the practical torque is less than the reference torque. At the position $\left.\theta\right|_{u(\theta)<-V}$, the decrement rate of the practical current is less than that of the reference current even though the phase is excited by the entire negative supply voltage $-V$. Thus, the practical torque is greater than the reference torque.

$\mathrm{TSF}_{\text {opt }}$ ensures that the required voltage does not exceed $V$ so that its reference current can be traced completely and the torque ripple can be eliminated (Fig. 15(e)). The simulation result indicates that at the point located on STSC, STO can be realized although it does not work well by using the other TSFs. Thus, the rationality of STSC is verified indirectly.

\section{Experiment Results}

The experimental setup of the SRM drive system is shown in Fig. 16. The current control with a hysteresis band of \pm $0.1 \mathrm{~A}$ is implemented by the controller RT_LAB. Instantaneous phase torque and total torque are estimated online according to the torque characteristics and are outputted via a digital-to-analog converter provided by RT_LAB. The 10-bit photoelectricity encoder determines the rotor position signals.

The experimental results are shown in Fig. 17. When the four conventional TSFs are executed (Figs. 17(a) to 17(d)) at the start of each conductive period, the phase current is unable to reach the reference current although the phase current increases to the maximum rate under excitation by the entire positive supply voltage,. Thus, the actual phase torque is less than the reference torque. At the end of the period, the phase current cannot decrease to the reference value under excitation by full negative supply voltage. Thus, the actual phase torque is greater than the reference torque. However, the torque error is small because of the small changing rate of the phase inductance at the tail of the current.

Therefore, the poor capability to trace the reference current causes torque ripples. To generate smooth torque, the speed or expected torque should be low. Thus, the operation range of STO using four conventional TSFs does not cover this operating point.

The optimal TSF considers the voltage demand; thus, the reference current can be traced well as shown in Fig. 17(e). However, at the beginning and end of the conductive period, the supply voltage has already been used entirely. If the speed or the expected smooth torque is higher than the present levels, the reference current cannot be traced completely and the torque ripple cannot be eliminated. Therefore, $(800 \mathrm{rpm}$, $0.45 \mathrm{Nm}$ ) is only on the STSC curve. The optimal TSF produces smooth torque over a wider range than the four TSFs do.

\section{CONCLUSIONS}

A scheme to determine the STSC of a given SRM was developed in this study in consideration of the supply voltage and peak current limit. The determined STSC defines the maximum operation range of STO. The voltage constraint does not exist at a low speed; thus, the maximum smooth torque is determined by the peak current limit. However, at a high speed, the range of the smooth torque depends on both the supply voltage and peak current.

A numerical iterative method was proposed to acquire $\mathrm{TSF}_{\text {opt }}$ that requires the minimum voltage $u_{\mathrm{r}_{-} \min }$. A $2 \mathrm{D}$ table of $u_{\text {r_min }}$ versus a series of discrete operating points over the speed-torque plane was calculated. All the points whose $u_{\text {r_min }}$ values are less than the supply voltage formed a set, which is the maximum operation range of STO. Then, STSC was created. 


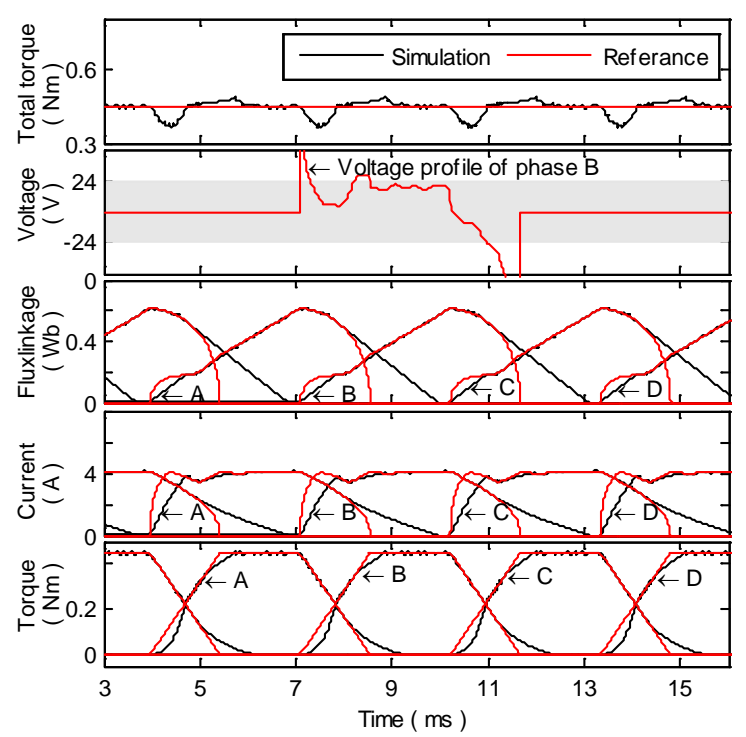

(a) STO using linear TSF.

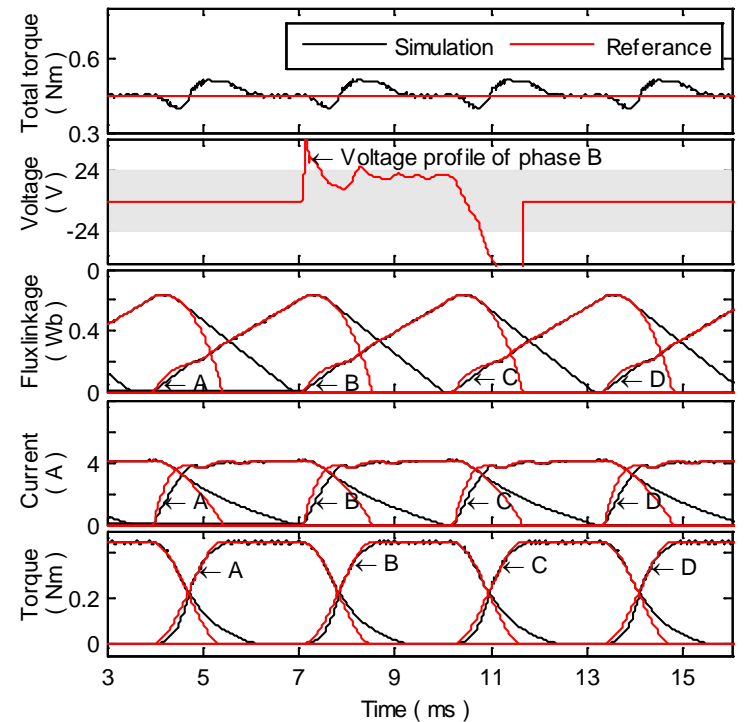

(b) STO using cubic TSF.

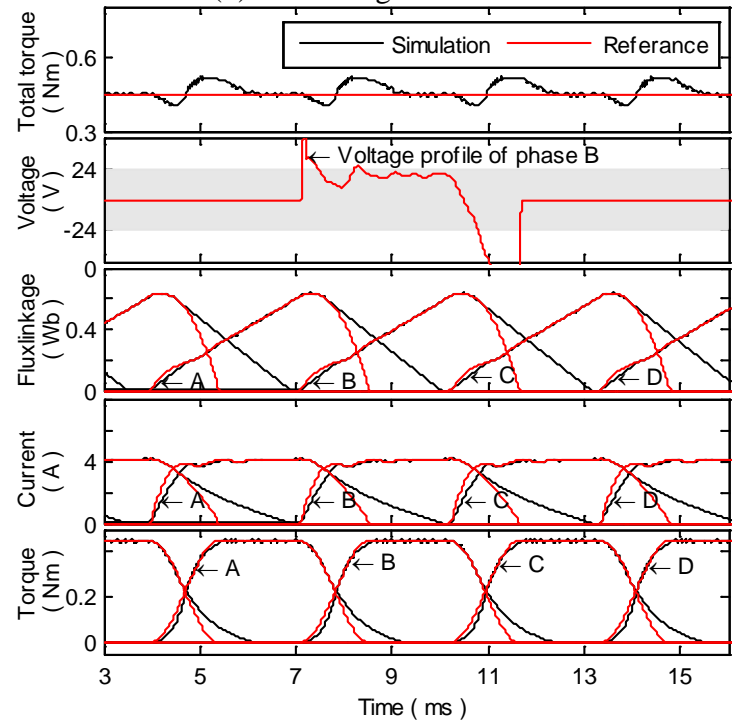

(c) STO using sinusoidal TSF.

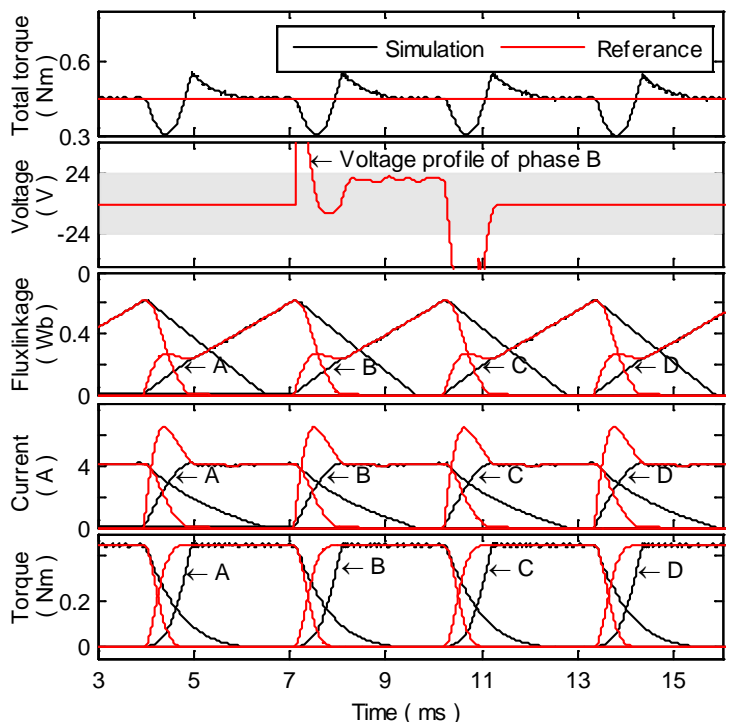

(d) STO using exponential TSF.

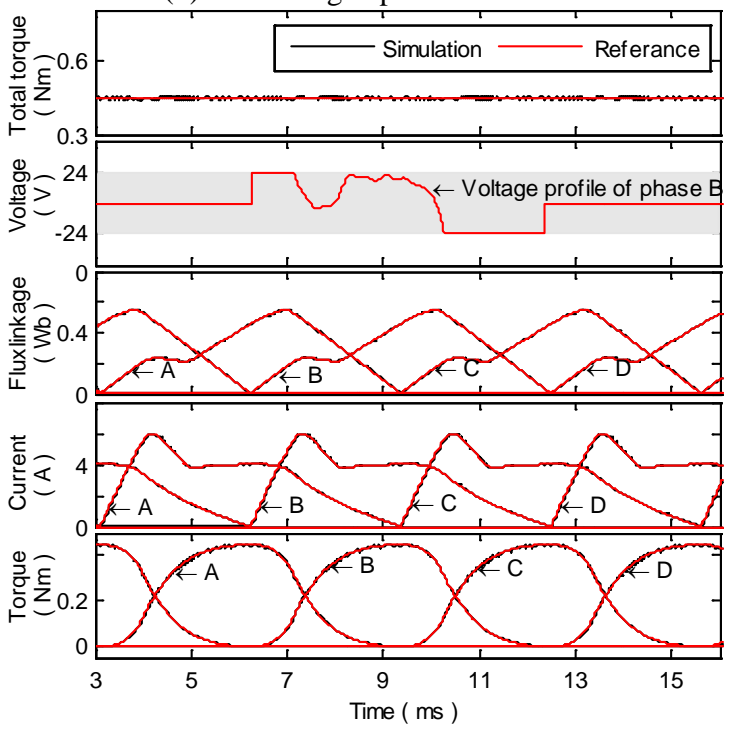

(e) STO using $\mathrm{TSF}_{\text {opt. }}$

Fig. 15. Waveforms of flux linkage, phase current, phase torque, and total torque using different TSFs $(\omega=800 \mathrm{rpm}, V=24 \mathrm{~V}$, $\left.T_{\mathrm{e}}=0.45 \mathrm{Nm}\right)$.

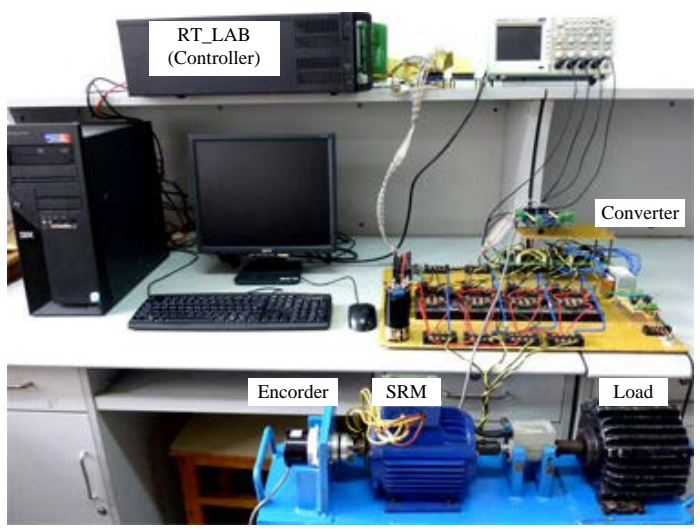

Fig. 16. Experimental setup of the SRM drive system. 


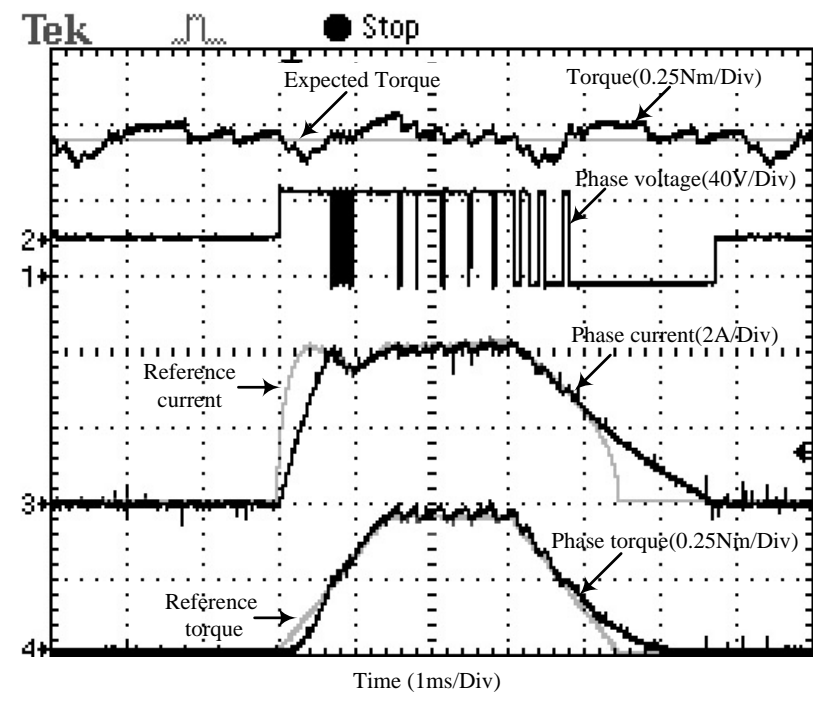

(a) Linear TSF.

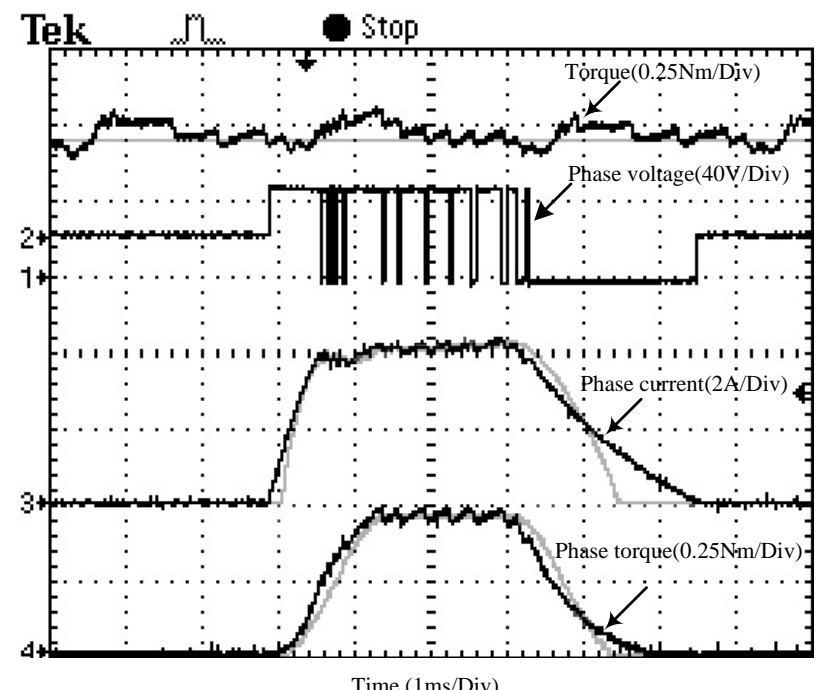

(b) Cubic TSF.

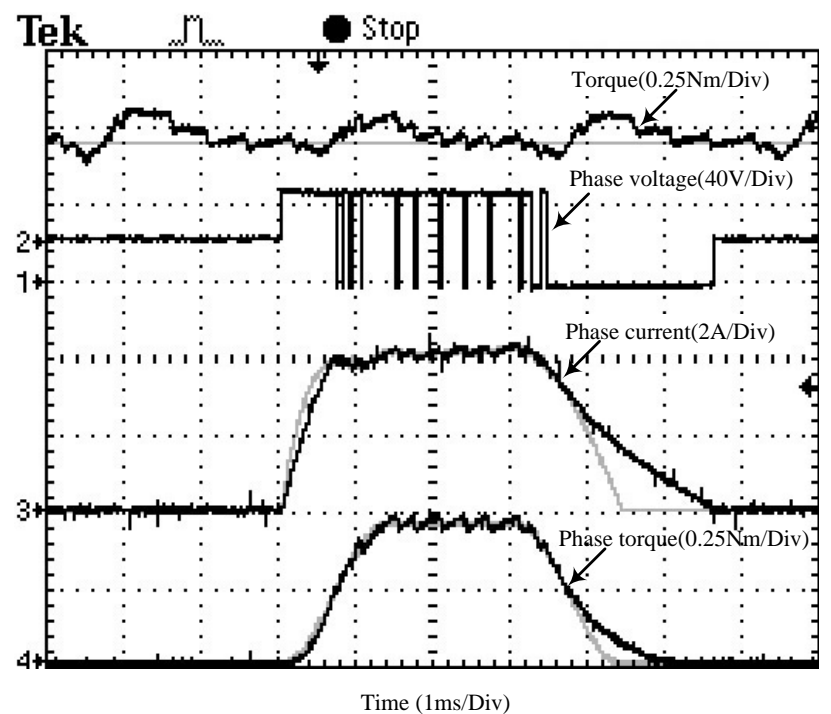

(c) Sinusoidal TSF.

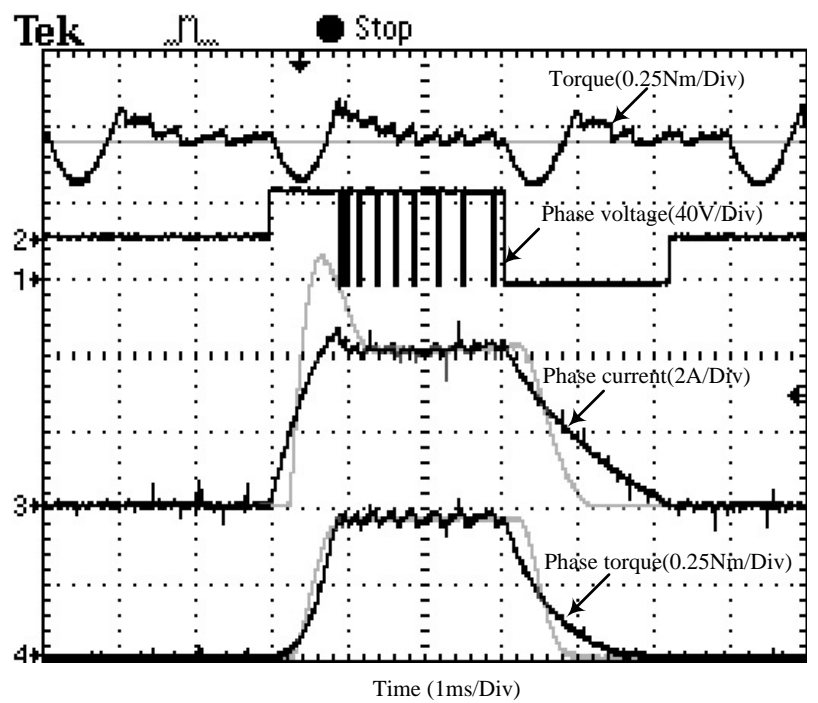

(d) Exponential TSF.

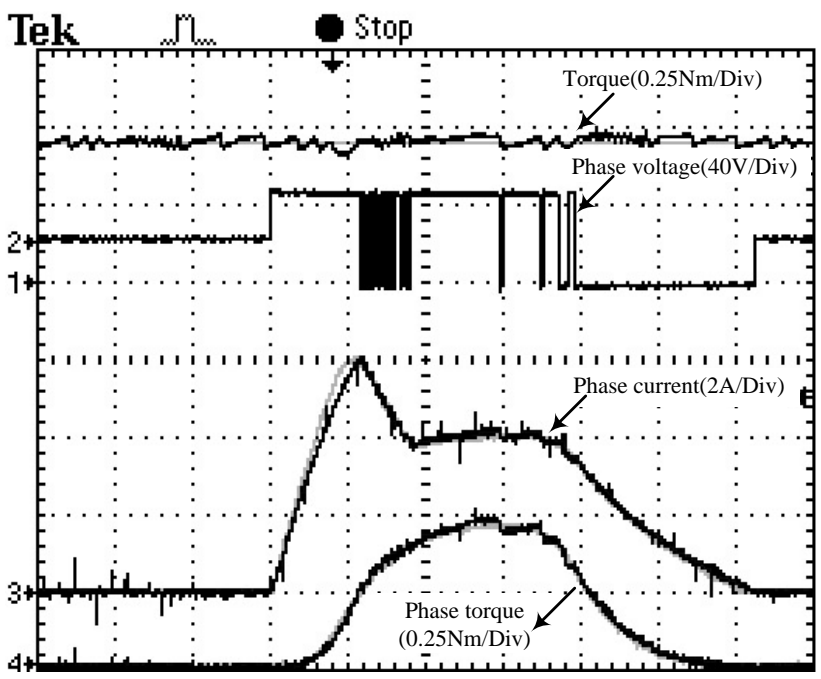

Time (1ms/Div)

(e) Optimal TSF

Fig. 17. Experimental results for the five TSFs at (800 rpm, 0.45 $\mathrm{Nm}$ ).

The generated STSC can be applied to evaluate torque utilization through comparison with TSC; this procedure is useful in designing special SRMs for smooth-torque operations. Furthermore, $\mathrm{TSF}_{\text {opt }}$ can be utilized to minimize the torque ripple. The co-simulation and experiment results show that $\mathrm{TSF}_{\text {opt }}$ can minimize the torque ripple well even at a high speed, whereas the four typical TSFs fail to do so. These results indicate that $\mathrm{TSF}_{\text {opt }}$ can be implemented over a wide operation range. The rationality of STSC was likewise verified.

\section{ACKNOWLEDGMENT}

This work was supported by the Danish Agency for Science, Technology and Innovation under the project "Dynamic wind turbine model - from wind to grid" 
(DSF-09-071588), the Joint Ph.D. Fellowship Program of the China Scholarship Council, the Specialized Research Fund for the Doctoral Program of Higher Education of China under Grant No. 20120095110019, and the University and College Industrialization Project of Jiangsu Province under Grant No. JHB2012-28.

\section{REFERENCES}

[1] R. S. Wallace and D. G. Taylor "A balanced commutator for switched reluctance motors to reduce torque ripple”, IEEE Trans. Power Electron., Vol. 7, No. 4, pp. 617-626, Oct. 1992.

[2] C. Moron, A. Garcia, E. Tremps, and J. A. Somolinos, "Torque control of switched reluctance motors," IEEE Trans. Magn., Vol. 48, No. 4, pp. 1661 -1664, Apr. 2012.

[3] P. C. Kjaer , J. J. Gribble, and T. J. E. Miller , "High-grade control of switched reluctance machines," IEEE Trans. Ind. Appl., Vol. 33, No. 6, pp. 1585-1593, Nov./Dec. 1997.

[4] J. M. Stephenson, A. Hughes, and R. Mann, "Torque ripple minimization in switched reluctance motor by optimum harmonic current injection," IEE Proc. Elect. Power Appl., Vol. 148, No. 4, pp. 322 -328, Jul. 2001.

[5] J. M. Stephenson, A. Hughes, and R. Mann, "Online torque-ripple minimisation in a switched reluctance motor over a wide speed range," IEE Proc. Elect. Power Appl., Vol. 149, No. 4, pp. 261-267, Jul. 2002.

[6] X. D. Xue , K. W. E. Cheng, and S. L. Ho, "Optimization and evaluation of torque-sharing functions for torque ripple minimization in switched reluctance motor drives," IEEE Trans. Power Electron., Vol. 24, No. 9, pp. 2076-2090, Sept. 2009.

[7] P. L. Chapman and S. D. Sudhoff, "Design and precise realization of optimized current waveforms for an 8/6 switched reluctance drive," IEEE Trans. Power Electron., Vol. 17, No. 1, pp. 76 -83, Jan. 2002.

[8] N. T. Shaked and R. Rabinovici, "New procedures for minimizing the torque ripple in switched reluctance motors by optimizing the phase-current profile," IEEE Trans. Magn., Vol. 41, No. 3, pp.1184 -1192, Mar. 2005.

[9] V. P. Vujicic, "Minimization of torque ripple and copper losses in switched reluctance drive," IEEE Trans. Power Electron., Vol. 27, No. 1, pp. 388 -399, Jan. 2012.

[10] A. M. Osama, H. A. Abdel Fattah and A. M. Sakr, "Variable structure flux linkage controller for torque ripple minimization in switched reluctance motors," in Proc. American Control Conference, Vol. 4, pp. 3105-3110, 2002.

[11] H. C. Lovatt and J. M. Stephenson, "Computer-optimised current waveforms for switched-reluctance motors," in Proc. IEE Electric Power Applications, Vol. 141, No. 2, pp. 45-51, 1994.

[12] H. C. Lovatt and J. M. Stephenson, “Computer-optimised smooth-torque current waveforms for switched-reluctance motors," in Proc. Inst. Electr. Eng.-Elect. Power Appl., Vol. 144, No. 5, pp. 310-316, 1997.

[13] F. Filicori, C. G. Lo Bianco, and A. Tonielli, "Modeling and control strategies for a variable reluctance direct-drive motor," IEEE Trans. Ind. Electron., Vol. 40, No. 1, pp.105-115, Feb. 1993.

[14] T. Y. Chuang and D. K. Lieu, “Optimized current waveforms for switched reluctance motors," in Proc. Electrical Insulation Conference and Electrical Manufacturing \& Coil Winding Conference, pp. 441-445, 1999.

[15] D. S. Schramm , B. W. Williams, and T. C. Green , "Torque ripple reduction of switched reluctance motors by PWM phase current optimal profiling," in Proc. PESC, Vol. 2, pp. 857-860, 1992.

[16] S. K. Sahoo, S. K. Panda, and J. X. Xu , "Indirect torque control of switched reluctance motors using iterative learning control," IEEE Trans. Power Electron., Vol. 20, No. 1, pp. $200-208$, Jan. 2005.

[17] I. Husain and M. Ehsani, "Torque ripple minimization in switched reluctance drives by PWM current control," IEEE Trans. Power Electron., Vol. 11, No. 1, pp. 83-88, Jan. 1996.

[18] M. Illic-Spong, T. J. E. Miller, and S. R. MacMinn, "Instantaneous torque control of electric motor drives,” IEEE Trans. Power Electron., Vol. 2, No. 1, pp. 55-61, Jan. 1987.

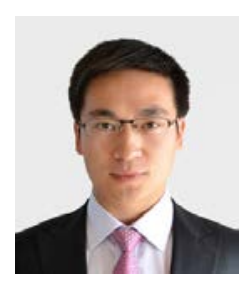

Hui Zeng received his B.S. degree from the School of Computer and Information Engineering, Hohai University, Changzhou, China, in 2008. He is currently pursuing his Ph.D. degree in the School of Information and Electrical Engineering, China University of Mining and Technology, Xuzhou, China.

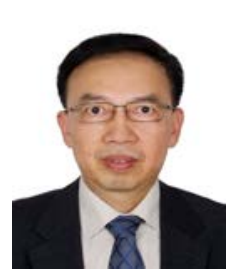

Zhe Chen (M'95-SM'98) received his B.Eng. and M.Sc. degrees from Northeast China Institute of Electric Power Engineering, Jilin City, China, and his Ph.D. degree from the University of Durham, U.K.

Dr. Chen is a full professor at the Department of Energy Technology, Aalborg University, Denmark. He is the leader of the Wind Power System Research Program at the Department of Energy Technology, Aalborg University and the Danish principal investigator for Wind Energy of Sino-Danish Centre for Education and Research. His research is mainly in the fields of power systems, power electronics, and electric machines. His current research interests include wind energy and modern power systems. He has led many research projects and has more than 360 publications in his technical field. Dr. Chen is an editor at IEEE Transactions on Power Systems, an associate editor (renewable energy) at IEEE Transactions on Power Electronics, a fellow at the Institution of Engineering and Technology (London, U.K.), and a chartered engineer in the U.K.

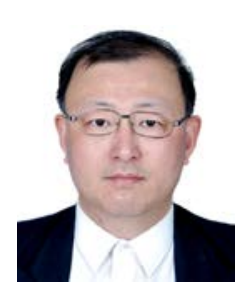

Hao Chen received his B.S. and Ph.D. degrees from the Department of Automatic Control, Nanjing University of Aeronautics and Astronautics, Nanjing, China, in 1991 and 1996, respectively. He became an associate professor in the School of Information and Electrical Engineering, China University of Mining and Technology, Xuzhou, China, in 1998. He has been a professor in the same institution since 2001. He was a visiting professor at Kyungsung University, Busan, Korea, from 2002 to 2003. Since 2008, he has also been an adjunct professor at the University of Western Australia, Perth, Australia. He is the author of one book and more than 170 papers. He has obtained 12 Chinese invention patents and six Chinese utility model patents. His current research interests include motor control, electric vehicles, electric traction, servo drives, and wind power generator control. Dr. Chen received an award each from the Science and Technology of Chinese Youth and the Fok Ying Tong Education Foundation for Youth Teachers in 2004. He was awarded the second prize in the Science and Technology Advanced of Province and Ministry six times and the third prize in the Science and Technology Advanced of Province and Ministry 12 times. He became a National Talent of the Chinese New Century Hundred-Thousand-Ten Thousand Talents Engineering in 2007. He was awarded a Government Special Allowance from the People's Republic of China State Department in 2006. 